\title{
THE TUBERCULOUS SOLDIER.
}

\author{
By G. SIMS WOODHEAD, \\ V.D., M.A., M.D., LL.D., LIEUT.-COLONEL R.A.M.C. (T.), \\ Professor of Pathology in the University of Cambridge ;
}

AND

P. C. VARRIER-JONES, M.A., M.R.C,S.,

Acting Tuberculosis Officer for the County of Cambridge and Hon. Medical Officer Cambs Tuberculosis Colony.

WhATEVER may have been opinions prevailing at the beginning of the war as to the effects of campaigning on the tuberculous subject, it has now been driven home, very forcibly, that men suffering from pulmonary tuberculosis can be of little use in the army. The effects of continued active service, the strenuous life in the field, hardship, lack of food, want of sleep, prolonged and severe exertion, fear and mental strain, along with sanitary conditions, necessarily far from perfect, have been seen to play a most important part in breaking down resistance to, and restarting, tuberculous processes in those already predisposed to tuberculosis, recovering from this disease, or subjected to infection by tuberculous material. In this war the static conditions under which our armies bave had to fight have to some extent counteracted the effects of the-open-air life, of ample and suitable rations, and of other elements favourable to the maintenance of health. Dr. G.S. Banks, of Aberdeen, amongst those who take a view opposite to this, maintains that any risk that soldier patients " may run" is more than counterbalanced by the general influence for good which attends a life led in the open air. This conclusion, however, has not been borne out by facts.

Other writers have undoubtedly quoted isolated cases in which tuberculous soldiers bave gone through hardships, without manifesting any untoward results at the time, but these writers have not been able to follow up their cases, and their conclusions can be of but limited value. Soldiers suffering from pulmonary tuberculosis have been proved to be of little use in the army; after a longer or shorter time they almost invariably break down, and soon pass beyond all hope of repair. This is well illustrated in an article by Dr. Thieme. ${ }^{1}$ This observer was so convinced of the value of the open-air life of the soldier in its effects on tuberculosis, that he strongly encouraged the enlistment of ex-patients. He had under his care, from rgo6 to $1915,1,200$ patients. "By means of the army authorities he was able to trace I, II7 of these expatients. It was found that 199 had died, 62. had been examined and

? Quoted in the British Medlinl Joumal, June ro, 1915. 


\section{IOO THE BRITISH JOURNAL OF TUBERCULOSIS}

rejected for military service, 28 had been accepted and subsequently rejected for ill-health, 24 had been called up to the colours and not yet passed, 24I were either at the front or doing garrison duty." Sixtyfour could not be traced. Of the 24I ex-patients who were either at the front or doing garrison duty, 187 had been in the first stage of the disease, 48 in the second, and 6 in the third. When they had been discharged from the sanatorium, 222 had been fit for work, IoI had been partly fit for work, and 7 had left the sanatorium before treatment had been completed. Such figures as these scarcely call for great enthusiasm as regards the rôle played by ex-sanatorium patients at the seat of war. It would have been more satisfactory from all points of view if Dr. Thieme had waited until the war was over, before he ventured to claim them as offering a striking proof of the success of sanatorium treatment.

\section{The Tuberculous Soldier in France.}

In France the problem of the tuberculous soldier is already receiving attention, and the danger of sending tuberculous soldiers straight back to their homes is becoming more and more fully appreciated. The Tuberculosis Commission has been negotiating with the Red Cross Society with a view to utilizing part of their resources for the creation of military convalescent homes and preventoriums, and agricultural colonies where tuberculous military men may be kept as convalescents or eventually discharged as unfit after a period requisite to re-establish them and instruct them how to live. In spite of all this, the essence of the problem, in France as elsewhere, remains untouched, as it is obviously useless to instruct a man how to live when he has not the means of following the advice given, or of putting those precepts, however sound in principle, into practice.

The problem is not only how best to "cure" or arrest the disease of a great number of persons who have either contracted the disease while on active service, or have suffered an extension of pre-existing disease under the strain of military duties; it is a something far wider and much more difficult of solution. How to protect the community from a source of infection which has greatly increased as a result of war conditions is the problem-the fundamental principle upon which the treatment and prevention of the disease alone can be carried out.

The same subject has, however, in times of peace engaged the attention and taxed the energies of public authorities all over the country, and it has been recognized that the only way to combat the ravages of tuberculosis is to prevent the spread of infection from one individual to the other. It is true that in time past we have been accustomed to concentrate our attention too much on restoring, if but temporarily, the health of individuals, and have recommended cases in the second 
and third stages of " consumption" for sanatorium treatment, of ten to the exclusion of earlier cases. We have filled our sanatoria with cases which could only benefit by such treatment for a short space of time, and which, returning too soon to their original surroundings, can only break down again and become sources of infection to other members of their families.

\section{The Care of Advanced Cases.}

The question of dealing with " advanced cases" of consumption is no longer a new one, and local authorities have been and are urged in no measured terms to provide accommodation for such cases; but the appeal falls on deaf ears, or at any rate on ears which are incapable of transmitting the message to the intelligence of the community. The type of accommodation that is offered to advanced cases of tuberculosis is unsuitable enough: either some beds at a Poor Law infirmary or a few beds in a ward of an isolation hospital-accommodation so obviously defective and insufficient for the needs of the civilian population that, when considered in connection with the discharged tuberculous soldier, is not only seen to be utterly inadequate, but unworthy of those discharged as no longer "fit" to serve in $\mathrm{His}$ Majesty's Army.

Are we justified in handing over our discharged consumptive soldiers to the Poor Law authorities, or in sending them for a few months to an infectious diseases hospital where they may be patched up, perhaps, and returned to their homes only to break down and succumb to the white scourge? Again, are we justified in offering to them domiciliary treatment by the Local Insurance Committee, and handing them over to the already overworked panel doctors, who, with the best intentions in the world, know how impossible it is to treat a case of advanced tuberculosis in a cottage ? The position from a purely humanitarian point of view is not only inadequate, but altogether unsound, while the position from the public health point of view is certainly not a matter for congratulation.

The error of our system is gradually becoming apparent, and we are coming to realize that treatment at a sanatorium, for the working man at any rate, should only be recommended for those in the early stages of the disease, in what at one time was spoken of as the "incipient stage." These cases after a suitable period of treatment may be returned to their homes, to suitable or some more favourable employment, with every prospect of their becoming of real economic value. Indeed, sanatoria supported by public money should only be used for such cases, for it is only by adhering very rigidly to this rule that the full economic value of sanatorium treatment is to be secured.

To fill our institutions with cases to be patched up temporarily and 


\section{IO2 THE BRITISH JOURNAL OF TUBERCULOSIS}

then discharged is to put these institutions to an utterly wrong and wasteful use, but under the present system of treatment of the tuberculous soldier this is exactly what we are doing. We appear to be afraid to tackle the question fully and firmly, and we seem to ignore the fact that the problem involves questions far more important than the individual treatment of the tuberculous patient.

Which of us is not familiar with the numerous schemes put forward for the treatment and care of the disabled soldier? But in not one of these schemes is the treatment of the tuberculous soldier brought in ; indeed, it may be said to be rigidly and constantly excluded. The treatment of the soldier who is disabled through the loss of an eye or eyes, of limbs, or other similar injury, is a comparatively simple matter to deal with. It may be, perhaps, on account of the greater difficulty in dealing with the tuberculous soldier that the matter has not yet been taken firmly in hand, but has been allowed to drift, things going steadily from bad to worse.

As the war goes on, we have undoubtedly a larger and larger percentage of soldiers suffering from tuberculosis discharged from the army, although it is now accepted that the preliminary medical examination is far more stringent and searching than it was during the first rush to the colours. In spite of this, however; the physique of the conscript compares unfavourably with that of the voluntary recruit; and if experience counts for anything, we must anticipate a still greater percentage of tuberculous soldiers.

\section{Question of Organization and Administration.}

Some of those who have studied this question most carefully are firmly convinced that the provision made for the treatment and aftercare of the soldier, devised and put into force by the War Office Authorities and the National Insurance Commissioners, will prove inadequate to cope with all that will be required of it, especially as, in delaying the treatment of the tuberculous soldier until he has been discharged from the army, there is involved the loss of the tremendous advantage of discipline. It appears to us that the after-care of the tuberculous soldier is an even more important question than it would be were steps taken to deal with the disease before the soldier leaves the army, and that it is essential that we should focus our attention on this after-care and study it in all its bearings, in order that not only a national but a rational scheme may be formulated. Isolated and local efforts can avail but little. It must, however, fall to the lot of some comparatively small body to crystallize the principles on which the after-care scheme can best be run; and an attempt has been made in Cambridgeshire, in the evolution of its after-care scheme, to insure that soldiers may share in the benefits, the provision of which has long 
been recognized as necessary for tuberculous civilians. One of the great advantages of a scheme providing for both civilians and soldiers is that it is capable of unlimited expansion, and, with modifications, of being adopted throughout the country.

To allow our tuberculous soldiers to drift into infirmaries and workhouses would be a blunder and a crime; to allow them to die in their own homes would be more than uncharitable and ungrateful. Here is an opportunity, then, of encouraging these men, many of them at the outset of an entirely new life, to make a fresh start in their old homes, if suitable, or of placing them in new homes where conditions are at least not so far from the ideal as in many of those formerly occupied by them. They may be assisted without any taint of pauperism being allowed to appear, they may be controlled without being fettered, helped to become a source of happiness to themselves, but not isolated or shunned in the fear that they may become a source of infection to others.

\section{Preventing the Spread of Infection.}

Nevertheless, although in any after-care scheme the responsibility of doing the best for the individual rests upon those who frame it, the even more important task of preventing the spread of infection to others has to be kept in mind and acted upon. Under existing conditions, each soldier invalided from the army whilst suffering from pulmonary tuberculosis may become a source of infection to the civil population, often almost immediately, and still more frequently in the course of three or four months. Many of them cannot be persuaded to undergo sanatorium treatment at all; others, after a very short period of discipline and treatment, having been away from home so long, weakened and disheartened, weary to join their friends, cannot be persuaded to continue under treatment for more than a few weeks, and they insist on returning to their homes, there to drag out a miserable existence, to infect the members of their families, and eventually to succumb to disease and poverty.

It is essential that we should realize how great an opportunity there now is, and also how rapidly it will pass away; and that unless a very efficient and complete scheme of after-care is devised and carried into effect, and this at once, the war is going to leave us with a heavy legacy of tuberculous patients on our hands.

With a well-thought-out scheme at our disposal, the individual, whether soldier or civilian, will stand a much better chance of being returned to health and strength; but, perhaps equally important, he will be rendered inert as regards the dissemination of infection to others. Such a golden opportunity must not be allowed to pass, and it is well worth our while to put forth strenuous and united efforts to solve 


\section{IO4 THE BRITISH JOURNAL OF TUBERCULOSIS}

some at least of the many problems involved in the treatment and aftercare of the tuberculous soldier.

\section{A National System of After=Care.}

The great and urgent need is for a rational and national system of "after-care." This has been recognized in the case of the civilian who returns from a sanatorium; there is an equally urgent need in the case of the discharged soldier.

It is obviously worse than useless to hand the soldier over to a lay committee, however anxious the members of that committee may be to do their part. The man's future life and conduct must be regulated from the medical point of view, though he must, of course, be provided with a satisfactory food allowance, whilst his home conditions should be made as favourable as possible. It is useless to allow a man to return to a two-roomed tenement, and tell him to "carry on" as he did at the sanatorium. He simply cannot do it. To apply the Cambridgeshire civilian scheme in the case of the discharged soldiers would be doomed to failure, on account of the more advanced stage of the disease in the soldier: no man is invalided from the army on account of tuberculosis who is not an open case. The Cambridgeshire scheme is only intended to include those cases suitable for sanatorium treatment and while the disease is in its infancy--i.e., where no tubercle bacilli have been demonstrated in the sputum-and to keep a patient with arrested disease until he can become a self-supporting member of the community.

\section{A National Scheme.}

With the discharged soldier, except in a small proportion of cases, a different plan must be followed. Such a plan must embrace the nation as a whole, as local endeavours are only mischievous and would be able to do nothing more than tinker with the problem. The question should be considered and decided under the following heads:

r. The treatment at a colony of the early cases, and their "aftercare "followed up as in the Cambridgeshire scheme.

2. The treatment of the second stage cases at a sanatorium whence they should be transferred to a colony for further treatment as in Case I, and their subsequent "after-care" taken in hand on land and in a settlement specially acquired for their reception, and on which their energies may be turned to remunerative account at some occupation-as nearly like their original work as possible.

3. The advanced cases should be kept under treatment at a central institution in the settlement; where they could be properly nursed, tended, and looked after, all danger of infection being eliminated. For 
single men this would work admirably, but with married men with families some difficulties would no doubt be encountered at the outset.

\section{Suitable Training must be Provided.}

The report on the effort to be made to place soldiers on the land ${ }^{1}$ should be followed as regards the after-care of soldiers discharged from the colony as early cases, as also with those discharged from the colony after undergoing their sanatorium treatment. They would then, eventually, be placed in houses on the settlement or estate where occupations would be found for them. Eventually they would form a nucleus around which to crystallize a tuberculous garden city.

A certain number of discharged soldiers would undoubtedly refuse treatment under this scheme, but from our experience we are convinced that, under proper medical supervision, discharged soldiers suffering from tuberculosis would gladly remove from unsuitable surroundings and migrate to the tuberculous garden city.

With the precautions which the health staff from the central building would be able to take in respect to the inmates of the cottages, the danger from the spread of infection would be reduced to a minimum; whilst, with suitable educational facilities that could be provided for the children in open-air schools in the village, the proper upbringing of the offspring would be assured.

The scheme would have to be financed by the State, but part of the outlay might be met by a certain fraction of the patient's pensions. This, together with the aid proffered by Friendly Societies, would put the married man into a fairly favourable position; whilst the money now expended upon the transient treatment of soldiers in sanatoria, usually followed by relapse at home, would be put to a sound use, and ultimately benefit the community by preventing the spread of infection.

Further, several counties are at the present time considering the desirability of segregating the advanced cases of tuberculosis; unless this is done humanely, more harm than good must result.

\section{Discharged Tuberculous Soldiers and Agricultural Work.}

The next step is to follow the instructions of the committee of recommendation ve discharged soldiers and the land. There some assistance from the State must be forthcoming. Money granted by the State for the purpose would be well spent, for there has never been such a golden opportunity to insure the segregation of advanced cases of tuberculosis and put a stop to the spread of infection. The measure brought to a successful issue would afford one of the finest examples of preventive medicine ever inaugurated.

- 1 See Departmental Committee on Land Settlement for Soldiers and Sailors. 


\section{Io6 THE BRITISH JOURNAL OF TUBERCULOSIS}

It is objected that the married man could not be separated from his family. This objection is more imaginary than real, for if a man is assured that his wife and children will not suffer-indeed, will be well cared for-he will in many cases readily consent to live apart from them. In support of this, we would point out that it is a matter of common experience that in time the diseased member of the family becomes a burden almost too great to be borne. How often do we find, for example, that the wife begs for her husband to be taken away and treated, "if it is for his good." And it is indeed for his good that such a course should be pursued; and not only for his good, but for that of the rest of the family. There are, of course, cases in which separation is impossible; the man is unable to work, and the wife has to go out and earn her own living. In such cases it will usually be found to be a matter of little difficulty to move the whole family on to the estate, where the man, his wife and family, can be kept under medical supervision, where the risk of infection under the ideal hygienic surroundings obtained would be far less than in a stuffy house in a cramped street; and we should find that, given a certain amount of liberty, the new conditions would soon become acceptable to the family.

It is anticipated that the whole plan here so briefly outlined would. gradually develop. The first phase, that of colony treatment, has. passed the experimental stage, and is now an accomplished fact; but our after-care scheme is needed to make the whole comprehensive in extent and sound in principle. The money spent on sanatorium treatment will no longer be wasted on merely palliative and temporary measures, but will help towards the provision of a preliminary training which will fit the patient to conditions of life which now present the best possible chance of recovery to himself, and of the prevention of the spread of infection to others.

\section{Co=ordination Necessary.}

The various financial questions concerned-Health Insurance, Friendly Society payments, and State contributions-are matters for further consideration. But since the money now expended on the various heads is, obviously, not only running to waste, but as used is. militating against the best interests of the community at large, it is surely extremely desirable to find a means of avoiding this waste, and of using any money available to the best and most lasting advantage.

There are at present too many central departments dealing with the problem of tuberculosis, and too many different local authorities whose divergencies are enhanced by the fact that they are supervised by different central departments. A unification of the central departments is greatly needed in order that there may be proper co-ordination of the efforts of the various local bodies, and an adequate active coherent policy adopted for dealing with this great problem. 